\title{
El debate sobre la ubicación de los cementerios en la España de las Luces: la contribución de Benito Bails
}

\author{
Juan antonio Calatrava *
}

Cuando se analiza algún aspecto relacionado directa o indirectamente con el urbanismo y las nuevas teorias sobre la ciudad en la Europa de las Luces, en la segunda mitad del siglo XVIII, es inevitable el referirse a un fenómeno aún no exhaustivamente estudiado en todas sus implicaciones: el de las incuestionables repercusiones que sobre dicho "urbanismo de las Luces" tuvieron los cambios que paralelamente se estaban desarrollando en otros ámbitos del saber, como la medicina, la física o la propia filosofía de la Naturaleza. En este contexto, se ha podido hablar de una auténtica preocupación "higienista" - bien diferente, por supuesto, a los parámetros que regirán el posterior higienismo urbano decimonónico- por parte de un amplio sector de científicos y pensadores de la llustración, sobre todo francesa. Dicha preocupación se plasmará en la existencia de toda una serie de propuestas innovadoras, que en bastantes ocasiones habrian de esperar mejores tiempos y no saltarian más allá del papel, con frecuencia chocantes para la mentalidad tradicional, y que se justificaban teóricamente desde un doble supuesto. En primer lugar, como actuaciones concretas encaminadas a lograr el ideal ilustrado de hacer más feliz la vida de los hombres, bien mediante el embellecimiento del entorno urbano o bien mediante realizaciones directamente materiales tendentes a dar respuesta a necesidades urbanas por vez primera sentidas como tales; desde esta perspectiva, se tratará de actuar sobre la ciudad del Antiguo Régimen introduciendo en ella criterios de racionalidad y eficacia que no pueden sino redundar en una mejora de las condiciones

\footnotetext{
- ETS Arquitectura, Madrid.
} 
de existencia para todos. Pero, además, en segundo lugar, dichas propuestas irán siempre teñidas del tono militante caracteristico del pensamiento de las Luces y se plantearán como actuaciones que trascienden su objetivo concreto para convertirse en símbolos de la lucha del philosophe contra la ignorancia, los prejuicios seculares y los abusos. El "pragmatismo de las Luces" de que hablaba Francastel se acompaña, así, de una fuerte carga utópica que nos obliga a no perder de vista el doble nivel de lectura implicito en toda reflexión ilustrada sobre la ciudad.

El problema secular de los enterramientos en el interior de las ciudades, y más concretamente, dentro de éstas, en el interior de las iglesias, se encuentra prácticamente desde mediados del siglo XVIII en el centro de tales preocupaciones. Numerosos médicos y científicos, franceses en un principio y más tarde del resto de los países en los que las Luces llegan a tener alguna implantación, insisten en la exigencia por motivos de salud pública de transferir los cementerios fuera de las ciudades ${ }^{1}$, contando para ello no sólo con el nuevo peso moral atribuido a la ciencia en detrimento de las razones teológicas, sino también con el recurso a una Historia en la que se quieren encontrar, desde Grecia y Roma, apoyaturas para tales disposiciones modernas, en un mecanismo muy habitual en el pensamiento de las Luces, que transfiere al tema concreto de los cementerios su visión global de la Historia humana como una lucha secular entre la Razón y el prejuicio.

Al mismo tiempo, amplios sectores de la iglesia católica apoyan tales iniciativas, aunque a menudo haciendo primar los intereses puramente litúrgicos o rituales o el anhelo por parte de un cierto sector avanzado del clero de reencontrar la pureza del cristianismo primitivo (versión específica del mito de los Antiguos) sobre la cuestión de la salubridad de los ciudadanos y la propia reforma de la ciudad. Así, resultarán imbricados con frecuencia dos tipos de problemas diferentes: el de la licitud o no desde el punto de vista eclesiástico de la inhumación en el interior de las iglesias y el de la transferencia de todo tipo de inhumación al extra. rradio de las ciudades. Imbricación ésta que no dejará en ocasiones de arrojar un cierto confusionismo sobre el debate.

En Francia, el arquitecto Pierre Patte condensa esta problemática en 1769 , en sus Mémoires sur les objets les plus importants de l'architectu-

'Vid., por ejemplo, EruIn, R., "L'air dans l'urbanisme des Lumières", Dix-Huitième Siècle, 9, 1977, págs. 122-134; ARIES, P., Essais sur l'histoire de la mort en Occident du Moyen Age à nos jours. París 1977; PETER, J. P., "Malades e maladies au XVIIIe siècle", en Annales. Economies, sociétés, civilasations, 1967, págs. 701-712; ETLIN, R., The Architecture of Death. The transformation of the Cimetery in the Eighteenth Century Paris. Cambridge 1984 . 
re, donde niega cualquier justificación histórica a la inhumación intramuros y exige la inmediata construcción de cementerios públicos extramuros, no sin prever grandes resistencias por parte tanto de intereses creados como de un vulgo dominado por el fanatismo y el prejuicio ${ }^{2}$. La actitud de Patte y de otros arquitectos, urbanistas y médicos iba a tener inmediato reflejo en una serie de disposiciones legales de los años finales del Antiguo Régimen, hasta llegar, ya en plena revolución, al decreto de 23 pradial del año XII que marcaría las bases del tratamiento juridico de la cuestión hasta fechas muy recientes.

En España, el debate tuvo un amplio eco, aunque con un relativo predominio -fácil de comprender- de las argumentaciones religiosas sobre las higienistas. La historia de la legislación ilustrada sobre cementerios y de las dificultades para su cumplimiento (con jalones tan importantes como la construcción, por orden de Carlos III y a iniciativa de Floridablanca, del cementerio de San lldefonso, la promulgación de la Real Cédula de 3 de abril de 1787, incluida en la Novísima Recopilación, o de la Real Orden de 26 de abril de 1804, la construcción del Cementerio del Norte en Madrid, según proyecto de Villanueva, las iniciativas tomadas durante la dominación francesa, o el fenómeno de los cementerios de las Sacramentales) escapa al límite del presente artículo, y ha sido parcialmente trazada ${ }^{3}$.

\footnotetext{
2 PATtE, P., “Article Cinquiéme. Nécessité de transférer la sépulture hors d'une Ville, et comment l'on y peut reussir", en Mémoires sur les objets les plus importantes de l'architecture. París 1769, págs. 41-47. Un resumen de las ideas urbanísticas de Patte en TEYssot, G. «llluminismo e Architettura. Saggio di Storiografia, publicado como introducción a la edición italiana de KaufmanN, E., Tre Architetti Rivoluzionari. Boulleee, Ledoux, Lequeu. Milán, Franco Angeli ed., 1976, págs. 40-48.

${ }^{3}$ Blanco Najera, M., Derecho Funeral. Madrid 1935; Corral, J. del, Los Cementerios de las Sacramentales. Madrid 1954; GonzALEZ DIAZ, A., "El cementerio español en los siglos XVIII y XIX, Archivo Español de Arte, 171, 1970, págs. 289-320; Bonet CORREA, A., "Les cimetiéres et l'architecture funéraire en Espagne et Amérique Latine", en AA.VV., Neoclassicismo. Atti del Convegno Internazionale promosso dal Comité Internationale d'His. toire de l'Art. Londres 1971; Saguar QUER, C., "La última obra de Juan de Villanueva. El Cementerio General del Norte de Madrid", Goya, 196, 1987, págs. 213-221 (sobre este mismo cementerio, MOleon Gavilanes, P., La arquitectura de Juan de Villanueva. El proceso del proyecto. Madrid 1988, págs. 200-208); SAGUAR QUER, C., "La aparición de una nueva tipología arquitectónica: el cementerion, en AA.VV., El arte en tiempo de Carlos III, IV Jornadas de Arte, Madrid 1989, págs. 207-217; Idem, "Problemas de higiene pública. El vientre de Madrid: muladares y cementerios", en AA.WV.: Carlos III, Alcalde de Madrid. Madrid 1988, págs. 501-518; Idem, "Carlos III y el restablecimiento de los cementerios fuera de poblado", en Fragmentos, 12-14, 1988, págs. 240-259. Una muestra de hasta qué punto el problema era sentido por nuestros ilustrados podemos verla, por ejemplo, en la anómala alusión de isidoro Bosarte, cuando habla de la arquitectura de los antiguos, a la existencia de un "decoro natural" que, en su opinión, se quiebra cuando se construyen en el interior de las ciudades hospitales o mataderos o se permite la sepultura (BOSARTE, 1., Observaciones sobre las Bellas Artes entre los Antiguos. Madrid 1790, Parte Tercera, pág. 49).
} 
Nuestro objetivo es, en este punto, llamar la atención sobre la publicación, en el mismo 1785 de un libro plenamente enmarcado en el debate y titulado Pruebas de ser contrario a la práctica de todas las naciones y a la disciplina eclesiástica y perjudicial a la salud de los vivos enterrar los difuntos en las iglesias y los poblados publicadas por $D$. Benito Bails. La figura de Bails, científico, matemático y teórico de la arquitectura, emerge cada vez con mayor nitidez en el panorama de las Luces españolas después de los más recientes estudios a él dedicados ${ }^{4}$. Educado en Francia, conocedor profundo de la cultura de las Luces del país vecino, frecuentador de algunos de los más importantes protagonistas de dicha cultura, Bails aparece sobre todo como uno de los principales responsables de la transmisión a nuestro país de las propuestas básicas de las Lumières. Profesor de matemáticas en la Academia de San Fernando desde 1768, "ejemplo vivo del soporte científico que todo el movimiento académico pretendió", en palabras de Navascués, Bails es recordado sobre todo por su magna obra Elementos de Matemáticas, entre los que se incluía un volumen de Arquitectura Civil que recibió forma de tratado independiente. En el detallado análisis efectuado por Navascués de la Arquitectura Civil, éste ha individualizado las diferentes fuentes, sobre todo - aunque no exclusivamente- francesas, en las que bebe Bails, concluyendo que tales fuentes son casi directamente plagiadas hasta dar como resultado una obra escasamente original. El papel de Bails aparecería así más como el de un introductor de ideas foráneas que como el de un pensador original (olvidándose que el propio Bails se quejaba de que la Academia no quería originalidad, sino mero resumen de fuentes).

Es sorprendente, sin embargo, que, en estas circunstancias, se siga hablando del libro que aquí nos ocupa como una obra original del propio Bails, ya que en Pruebas de ser contrario... ni siquiera es necesario acudir a un examen interno del texto para rastrear sus posibles fuentes, sino que basta con echar una ojeada al índice para darse cuenta de que se trata de una mera compilación de textos ajenos. En efecto, pese a la ambigüedad que el título y el Prólogo podrian provocar sobre la verdadera autoría del volumen, lo cierto es que dicho prólogo es lo único escrito por Bails ${ }^{5}$, componiéndose el libro de cuatro escritos independien-

"Bedat, C., «Don Benito Bails», Academia, 27, 1968, págs. 19-50; Granell, C. “Un ilustrado español: Benito Bails", Carrer de la Ciutat, noviembre 1977, págs. 5-7; SAMBricio, C., "Benito Bails y la arquitectura española de la segunda mitad del siglo XVII", La Arquitectura española de la llustración. Madrid 1986, págs. 129-146; NAvAscues, P., "Estudio crítico introductorio a BAILS, B., De la Arquitectura Civil. Murcia 1983, vol. I.

${ }^{5}$ Dice así el Prólogo de Bails: 
tes recopilados y, en su caso, traducidos por él, y que aparecen citados claramente con los nombres de sus respectivos autores y la fecha de su publicación original. Con lo cual se nos vuelve a mostrar Bails aquí como divulgador y transmisor más que como teórico independiente. No cabe duda, sin embargo, de la intencionalidad iluminista de Bails al reunir y dar a la imprenta en España estos textos, y cabe preguntarse si es lícito al historiador menospreciar su labor olvidando las urgencias y la dureza con que a la altura de 1785 se presenta el combate por las Luces en España. Deliberadamente hemos utilizado en el título de este trabajo la expresión «la contribución de Bails»: contribución esencial que ha de medirse, en este caso, por su capacidad para mantener abiertos los canales de comunicación con las Luces europeas en un momento en que sobre nuestros ilustrados, nunca muy firmemente asentados, planeaba ya la sombra de la involución finisecular.

El primero de los textos compilados por Bails es una Disertación sobre el lugar de las sepulturas originalmente publicada en italiano, en 1774, por el abate Scipione Piattoli, cuya azarosa carrera le llevaria desde ser profesor en Módena hasta convertirse en 1789 en hombre de confianza del rey Stanislas de Polonia, ejercer misiones de espionaje, pasar seis años en las cárceles austriacas y gozar, a partir de 1803, de cierta influencia en la orientación de la política exterior rusa ${ }^{6}$.

El escrito de Piattoli, que fue traducido también al francés, es un texto de carácter predominantemente histórico-crítico, destinado a suministrar argumentos que avalen con el peso de la historia el objetivo final declarado desde un principio: demostrar «... que en todos los tiempos y en todas las naciones se ha tenido por necesario apartar de los poblados las sepulturas por los daños que causan las exhalaciones de los cadáveres" ?. Desde esta perspectiva, enfoca el abate italiano el análisis y descripción de la "práctica de los diferentes pueblos en punto a sepulturas" y para ello efectúa, de partida, una interesante diferenciación entre

con la extensión y las razones que yo deseaba y convenia cuánto perjudica a la salud de los hombres y repugna con la Disciplina Eclesiástica y la práctica de la Iglesia de España enterrar a los muertos en las Iglesias y poblados. Poco antes de que se publicara mi Obra dio el Gobierno algunas providencias para atajar el daño y escándalo que de esta práctica se sigue. $Y$ pareciéndome muy necesario imponer silencio con la evidencia a la malignidad, prevenir con la razón a los incautos e ilustrar con la doctrina a las personas que ninguna obligación tienen de saber estas materias, determiné dar a luz separadamente las noticias conducentes para conseguir fines de tanta importancia. Si no se consiguen todos, quedarán por lo menos demostrado que la verdadera piedad nada padecerá de las medidas que sobre ésto se van a tomar pues las pide y abona la misma Religión», (Op.cit., s.p.).

- Noticias sobre Piattoli en la voz correspondiente de la Enciclopedia Italiana y en D'ancona, A. Scipione Piattoli e la Polonia. Florencia 1915.

7 Pág. 1. 
el enfoque del historiador y el del filósofo. Negando implícitamente la posibilidad de una historia "filosófica", como la perseguida por Voltaire, caracteriza al historiador con los rasgos de un mero erudito que colecciona hechos sin reflexionar sobre los mismos, mientras que reserva para el «filósofo" la auténtica tarea creadora de indagar las razones profundas de tales hechos ${ }^{8}$. Se reproduce así la sempiterna diferenciación que la cultura de las Luces establece entre la compilación y el pensamiento creador, entre la simple enumeración y descripción de hechos u objetos y la capacidad de trascenderlos en aras de una nueva espiritualidad, aunque es insólita aqui la desvalorización de la figura del historiador, nueva figura de auténtico "philosophe» que con frecuencia se oponía idealmente al viejo "erudito".

Así, para Piattoli, el que analiza los hechos históricos con la actitud del filósofo, y no los colecciona como el historiador, sabe discernir del cúmulo de tales hechos y de su variedad algunas constantes básicas en el terreno que nos ocupa. En el paso de la barbarie a la civilización puede descubrirse, por ejemplo, según Piattoli, el hecho fundamental de que, por más variedad de costumbres funerarias que se puedan encontrar, la sepultura o inhumación es la única que se corresponde con el desarrollo de la civilización.

Sin embargo, una vez establecida esta tesis de partida, que ofrece la llamativa particularidad de excluir de la "civilización" a las culturas de la cremación, la historia concreta de las modalidades de inhumación entre los diferentes pueblos aparece en las páginas del texto, según la mejor tradición historiográfica del discurso iluminista, como un episodio más de la secular lucha entre el abuso, los prejuicios y el fanatismo, por un lado, y, por el otro, las Luces de la Razón, cuya difusión se encuentra siempre en manos de una pequeño grupo de hombres a quienes debe la sociedad gran parte de sus avances. Es muy significativo, en este sentido, que encontremos una inequivoca alusión al mito ilustrado del legislador primitivo, ideal antecesor del philosophe, fustigador de abusos y destructor de prejuicios. Refiere así Piattoli cómo el prejuicio de querer tener a la vista el cadáver de un ser querido fue desterrado en los comienzos de la historia por esos «...hombres ilustrados cuyo destino era dilatar los límites del entendimiento humano, dictar leyes y desterrar abusos" ${ }^{9}$. Así, desde el principio de los tiempos, la Razón del filósofo lucha por el con-

${ }^{8}$ Alude, por ejemplo, a la gran variedad histórica de ceremonias fúnebres a... que los Historiadores refieren sin pararse, pero de las cuales el Filósofo indaga y cala el objeto y los motivos" (pág. 7).

${ }^{8}$ Pág. 7. 
trol de unas pasiones que, desbordadas, no pueden generar sino la irracionalidad, y los reformadores modernos que chocan con la incomprensión del vulgo y el orgullo de los grandes cuando promueven la prohibición de inhumar en las iglesias o en el interior de las ciudades son así históricamente equiparados a los Solón o Licurgo. Y la actuación primigenia del legislador da como resultado una primera victoria sobre lo irracional:

«En medio de tantos estilos introducidos en diferentes pueblos por el capricho y la vanidad, la naturaleza, las leyes y la religión han constantemente convenido, según se infiere de lo dicho, en apartar los muertos de los vivos, y nunca se han olvidado las miras con que las sepulturas se hicieron lejos de los pueblos" ${ }^{10}$.

Dicha unanimidad histórica en cuanto a la inhumación en despoblado se desarrolla al examinar el autor, con un neto espíritu de erudición anticuaria, la problemática de las sepulturas entre hebreos, griegos y romanos. En el epígrafe sobre "Sepulturas de los Hebreos" ", ya es de por si significativa la aparición del pueblo bíblico como autoridad histórica junto a griegos y romanos. Evidentemente, juegan aqui las razones religiosas de entronque entre la tradición judaica y la cristiana, pero sin duda no es casual que esta alusión a la historia hebraica sea contemporánea a la reivindicación de tipo prerromántico realizada por Herder y otros en el contexto de disolución de las certezas ilustradas y de búsqueda de nuevas vias históricas ajenas a la herencia grecorromana. En cuanto al contenido de este epígrafe, no es sino un cúmulo de relatos bíblicos de los que se deduciría la práctica del enterramiento extramuros por parte de ios judios, todo ello mezclado, sin embargo, con ejemplares muestras de la crítica ilustrada contra los aspectos más supersticiosos de las religiones (se detiene Piattoli, por ejemplo, a desmontar y calificar de ridícula la tradición rabínica sobre la historia de los huesos y la calavera de Adán).

En cuanto a los griegos, comenta ampliamente la legislación de SoIón o las prescripciones platónicas de la República, llegando a afirmar que “...ninguna nación se esmeró más que la griega en dar a los muertos los honores de la sepultura" ${ }^{12}$. Por lo que respecta a Roma, expone

10 Pág. 17. Es significativo que muestre Piattoli, además, preocupaciones de orden netamente fisiocrático cuando añade la exigencia de que "por amor de la agricultura" se elijan terrenos incultos y estériles (pág. 8).

11 Págs. 18-23.

12 Pág. 25. 
con gran detallismo las vicisitudes históricas y legislativas de la prohibición de enterrar en el interior de las ciudades a partir de la Ley de las XII Tablas ${ }^{13}$.

Hebreos, griegos y romanos no constituyen, sin embargo, más que un exordio destinado a mostrar la universalidad de unas disposiciones de las cuales lo que verdaderamente interesa es su andadura en el período cristiano. $Y$ ello porque la intencionalidad del texto de Piattoli es doble: no solamente, como ya se ha dicho, reivindicar la construcción de cementerios extraurbanos sino también, y sobre todo, remachar la idea de que la práctica de las sepulturas en las iglesias es un abuso que no tiene nada que ver con los principios de la verdadera religión y que, por tanto, puede y debe ser desterrado sin merma alguna para tales principios.

La historia del cristianismo tal y como la expone Piattoli no deja de presentar, de nuevo, los ribetes de la crítica ilustrada, puesto que se contempla dicha historia como la evolución desde un cristianismo primitivo puro y mantenedor de los verdaderos principios hasta un periodo posterior, el de la oficialización de la Iglesia desde Constantino, a partir del cual van abriéndose camino toda clase de abusos y corrupciones pese a la esporádica y titánica labor de algunos individuos excepcionales, santos o legisladores.

Así, si las sepulturas de los primeros cristianos seguían manteniendo el enterramiento extramuros, gracias a la loable actitud de mantener del paganismo todo aquello que más que pagano fuese natural y racional, después de Constantino, sin embargo, la institucionalización y la consiguiente construcción masiva de templos en el interior de las ciudades marcan el comienzo de la época de corrupción. Poco a poco aumentan las excepciones que permiten el enterramiento en el interior de las iglesias:

"Con el tiempo creció tanto el desorden que se concedió indistintamente a los gentiles y a los cristianos, a los impios y a los que habían vivido una vida ejemplar, la sepultura en lo interior de los templos" ".

Esta proliferación de sepulcros en las iglesias marca en un cierto sentido la evolución arquitectónica del templo cristiano, ya que de ella hace derivar Piattoli la aparición de las naves laterales:

\footnotetext{
13 Págs. 26-34.

i4 Pág. 46.
} 
"Este es el origen de las capillas, adonde se retiraban los fieles cuando querian recogerse, meditar o rezar sobre las sepulturas. Al principio estuvieron separados de las iglesias estos edificios, después los arrimaron por medio de pórticos o arcos, que se estilaban particularmente en la edificación de las Básilicas, y formaron las naves laterales, que aún hoy día señalan la importancia y antigüedad de una iglesia; al fin, se cerraron, por todos lados y formaron todo un cuerpo con lo demás del edificio" ${ }^{15}$.

El resto del texto de Piattoli reseña, anticipando al escrito subsiguiente de Ramón Cabrera, numeroso intentos de reacción contra este abuso por parte de los poderes públicos y, sobre todo, de las autoridades eclesiásticas, las cuales - se insiste- nunca autorizaron tal proceder, que es imputable sobre todo a la vanidad de "los grandes". Poder público y eclesiástico aparecen, pues, aquí, como defensores hermanados de la Razón frente a abusos que provienen del fanatismo del vulgo o de los mezquinos intereses privados de los poderosos:

"... se echa de ver que los príncipes más ilustrados han constantemente mantenido con su autoridad, en punto de sepulturas, lo que más convenía al bien de los pueblos. Las antiguas constituciones eclesiásticas, las cartas de los Pontífices, la tradición inalterable que hacían vanidad de guardar, todo concurría al parecer a preservar las Ciudades de la infección de los cadáveres; pero, lejos de desterrarse, el abuso se fue afianzando cada día más" ${ }^{16}$.

Así, el problema de la sepultura en las iglesias, tal y como es recibido por el siglo XVIII, presenta para Piattoli una clara continuidad: si, desde Teodosio o Carlomagno a San Carlos Borromeo, las jerarquías civiles y eclesiásticas han luchado contra el abuso sin conseguir suprimirlo, la actuación del príncipe contemporáneo al dictaminar, esta vez con reales posibilidades de éxito, el enterramiento fuera de las ciudades y, de acuerdo con la autoridad eclesiástica, la prohibición de la inhumación en los templos, no puede considerarse en modo alguno como un ataque laico y absolutista contra una tradición religiosa, sino como el cumplimiento final de un designio largamente perseguido, por fin realizable gracias al progreso de las Luces, y que persigue el aunar la salud pública y las nuevas exigencias higienistas con la idea de una restauración de los

\footnotetext{
15 Págs. 47-48.

16 Pág. 56.
} 
verdaderos principios cristianos. $Y$ un índice claro de que la problemática del cementerio dieciochesco no puede leerse únicamente en clave higienista es el hecho de que, al concluir, insista Piattoli sobre todo en el segundo aspecto citado:

"De todas estas autoridades deben inferirse que la práctica de enterrarse en las Iglesias que se estila en estos tiempos debe desterrarse como contraria a las máximas de la Religión" ${ }^{17}$.

El segundo de los textos recopilados por Bails es una Disertación histórica en la cual se expone según la serie de los tiempos la varia disciplina que ha observado la Iglesia de España sobre el lugar de las sepulturas desde los tiempos primitivos hasta nuestros dias, firmada por el sacerdote Ramón Cabrera, destacado lingüista y especialista en Derecho Canónico. La disertación de Ramón Cabrera, escrita originalmente en 1775, desarrolla argumentos religiosos similares a los de Piattoli, pero insiste, en mucha mayor medida que el italiano, en los temas higienistas y de protección de la salud pública, configurándose como un ejemplo modélico de la producción de los clérigos reformistas e ilustrados españoles en su intento por lograr un maridaje entre las nuevas ideas, convenientemente depuradas, y el dogma religioso, igualmente depurado de sus añadidos más supersticiosos e irracionales ${ }^{18}$.

El hilo conductor del discurso de Cabrera es, así, la crítica contra la ignorancia y la superstición de los fieles que sustituyen la verdadera religión por un cúmulo de absurdos. Se alza Cabrera, con palabras que trazan un vivo retrato de los duros obstáculos con que tropezaba en España la difusión de las nuevas ideas, contra la extendida acusación de "extranjerismo" que se opone a la difusión de las tesis de la nueva medicina ilustrada y a la insistencia de ésta en el tema de los cementerios extramuros:

17 Pág. 69.

18 Sobre la "ilustración cristiana", vid., por ejemplo, entre una amplísima bibliografia, SaugnieuX, J., Foit et Lumières dans l'Espagne du XVIIle siècle. Lyon 1985: Idem, Le Jansenisme espagnol du XVIIle siècle. Oviedo 1975; Idem, La llustración católica en España. Escritos de D. Antonio Tavira. Salamanca-Oviedo 1986; ToMsICH, M. G. El Jansenismo en España. Estudio sobre las ideas religiosas en la segunda mitad del siglo xvil. Madrid 1972; AA.VV. La Iglesia en la España de los siglos xVII y xVIII, t. IV de Historia de la lglesia en España. Madrid 1987. Para una referencia bibliográfica más detallada, es fundamental la consulta de los repertorios que publica periódicamente el Centro de Estudios del Siglo XVIII de la Universidad de Oviedo. 
"Cuando se objeta a las gentes arriba mencionadas que en la mayor parte de las Provincias Católicas se ha resuelto después de un maduro examen construir cementerios comunes fuera de los pueblos, no encuentran reparo en responder que éstas son unas novedades introducidas por unas personas empeñadas en trastornarlo todo y en desterrar de las Repúblicas, con el pretexto de perniciosos, los usos más antiguos y piadosos; y al argumento que se toma de lo que se practica fuera de España, contestan diciendo que en los reinos extranjeros no está la Religión tan atendida como en la Península» ${ }^{19}$.

Cabrera se propone, por el contrario «...manifestar que lo que reputa como una costumbre inveterada y religiosa es un detestable abuso" ${ }^{20}$.

Para ello combina el autor la argumentación histórico-religiosa con la científica. En particular esta última alcanza un prolijo desarrollo en la segunda parte del texto, donde trata de explicar, acudiendo a las teorias de la ciencia contemporánea, los procesos de corrupción del aire por la putrefacción. Pero el mayor interés de esta segunda parte es la tesis de Cabrera de que lo dicho sobre los daños provocados por los enterramientos en el interior de las iglesias debe aplicarse igualmente a los efectos de los cementerios en el interior de las grandes poblaciones. Cabrera logra así conectar de modo mucho más directo que Piattoli la mera preocupación eclesiástica por la reforma de los modos de enterramiento en lugar sacro con las tesis urbanísticas del higienismo de las Luces; y, en la linea de lo planteado en Francia por Pierre Patte, propugna ya claramente la construcción de cementerios fuera de las ciudades, para la cual da incluso algunas normas elementales como el que se encuentren en campo raso, que estén en sitio seco y despejado donde tengan fácil acceso los vientos del Norte o del Este, o que no se planten árboles que impedirian la circulación del aire ${ }^{21}$.

En cuanto a la parte primera de su disertación, la propiamente histórica, deja Cabrera de lado a hebreos, griegos y romanos y aborda la descripciói de las costumbres funerarias de los españoles en cuatro períodos a los que corresponden otros tantos capitulos: "los españoles cris-

19 Págs. 74-75.

20 Pag. 75.

21 Recomendación ésta expresada por Bails iguaimente en su Arquitectura Civil, donde afirmaba que las raices de los árboles “...estorban a los sepultureros hacer las hoyas y perjudican notablemente a las paredes de las iglesias, sus ramas forman una especie de cubierto que detiene los vapores fétidos y estorba circule el aire con la facilidad que circularía estando abierto el cementerio a todos vientos, cuya disposición es mejor que otra cualquieran (págs. 837 de la ed. cit.). 
tianos bajo la denominación de los romanos gentiles", "bajo la dominación de los romanos católicos", "bajo la dominación de los godos arrianos" y "bajo la dominación de los Reyes Católicos desde Recaredo hasta nuestros días".

Afirma en el primero, como Piattoli, que los primeros cristianos siguieron la lección de Cristo, quien, al fundar la Iglesia, no pretendió abolir leyes anteriores que fuesen justas y beneficiosas. Los cristianos acatan, así, las normas romanas sobre enterramiento, y ello no por temor sino por una convencimiento racional que les hace incluso mantener, de la normativa romana, sólo el motivo de utilidad pública, eliminando todo lo que pudiera haber de supersticioso. En el segundo período, el del cristianismo tardorromano, registra ya la aparición de los primeros problemas, deteniéndose largamente en la discusión historiográfica y jurídica (entre otros autores aparece citado, significativamente, Muratori) sobre la interpretación exacta de la legislación teodosiana sobre enterramientos. En el tercero aparece, igualmente, una amplia disgresión sobre las distintas leyes vigentes en el reino visigodo, enumerándose las frecuentes prohibiciones de enterramiento intramuros emitidas por los Concilios.

Mayor interés reviste el capítulo cuarto, "desde Recaredo hasta nuestros días". Alude en él Cabrera (tras un largo desarrollo de indudable interés historiográfico, aunque fuera de los límites del presente artículo, sobre la utilidad que acarrearía publicar la compilación de cánones de los Concilios) a la tenaz defensa eclesiástica de la norma prohibitiva. Registra la aparición del fenómeno arquitectónico de las capillas para responder a las excepciones en caso de personas reales (para la descripción del Escorial remite a Ponz). Pero al mismos tiempo ve en este período, lo mismo que Piattoli, el comienzo de la corrupción al irse extendiendo a personas privadas el privilegio antes estrictamente reservado a obispos y personas reales: primero los poderosos, luego las personas "de mediania", y al final incluso los cómicos, logran hacerse enterrar en las iglesias (es evidente que el reformismo de Cabrera no logra aquí traspasar el umbral del secular desprecio eclesiástico hacia el teatro) ${ }^{22}$.

Sin embargo, Cabrera mantiene el estricto orden del discurso historiográfico ilustrado haciendo suceder a una larga época de oscuridad un brillante momento contemporáneo marcado por un nuevo advenimiento de las Luces. En este sentido, toda la parte final de su texto es una loa a la labor de diversos personajes contemporáneos que protagonizan la lucha contra el abuso.

22 Cabrera alude a los actores como "...aquellos cuya profesión siempre ha detestado y detesta la Iglesia" (pág. 138). 
Así, dos eclesiásticos resumen, en el tema de los enterramientos, la postura del sector más abierto del clero. Se trata del arzobispo de Barcelona, J. Climent ${ }^{23}$, de quien se menciona su orden de construcción de un cementerio pero, sobre todo, en la línea de lo que recomendaba $P$. Patte, su prudencia en la lucha contra el fanatismo popular ${ }^{24}$. En segundo lugar, del arzobispo de Granada Antonio Jorge Galván, del que Cabrera relata cómo se dirigió el Consejo de la Cámara proponiendo la construcción de cementerios en las iglesias para aumentar el aseo del templo y duración de sus suelos, y cómo, significativamente, la idea es aprobada pero añadiéndose por parte de Campomanes a los motivos expuestos el mucho más importante de la salud pública ${ }^{25}$. Precisamente el elogio de Campomanes que se contiene en este punto es prueba inequivoca del alineamiento reformista de Cabrera: «...este docto magistrado a cuyas superiores luces y celosa actividad es deudora toda la nación de tantos establecimientos útiles" ${ }^{26}$.

Pero, junto a los dos clérigos y Campomanes, aparecerá finalmente el propio Carlos III y la mención al cementerio de San Ildefonso, con el deseo de ver su ejemplo extendido a toda España:

"Por último, nuestro prudentísimo y religioso Monarca Carlos III, que con tan benigno semblante oye las proposiciones que miran al bien estar de sus vasallos, habiéndole expuesto su vigilante y sabio Ministro de Estado el Excmo. Sr. Conde de Floridablanca las utilidades que podrian resultar al Real Sitio de San lldefonso enterrándose los cadáveres fuera de la población, se ha dignado mandar construir a distancia como un quarto de legua de dicho Real Sitio un Cementerio para todos los que alli muriesen. ¿Qué acertado sería que esta favorable providencia se extendiese a los demás pueblos de la Nación! Todo se puede esperar de un Rey que tanto aprecio hace de los títulos de Padre de la Patria y Protector de los Cánones: y que además no ignora que el primer dictado le empeña a proveer cuanto concierne ser conducente a la salud pública; y el segundo a imponer echando mano de su autoridad sobre la cenviz de los soberbios, como dice San Isidoro de Sevilla,

23 TORT Mitjans, F., El Obispo de Barcelona Josep Climent i Avinent (1706-1781). Barcelona 1978 (especificamente págs. 250-153).

${ }^{24}$ Conocedor de los errores del pueblo, ve que usar el poder es contraproducente y trata de a...conducir este delicado negocio por el camino de la suavidad, dando tiempo a que los fieles depusiesen sus engaños" (pág. 145).

${ }^{25}$ Sobre el caso especifico de Granada preparamos actualmente un artículo aparte. El trabajo de Diaz Guervos, I. y DIAZ GaRcía, A. "Notas sobre la historia del cementerio de Granada", en Revista del Centro de Estudios Históricos de Granada y su reino, segunda época, 2, 1988, págs. 177-197, prácticamente no contiene referencias al período que aquí nos interesa.

${ }^{26}$ Pág. 146. 
"aquella disciplina que por medios suaves no puede la Iglesia hacer observar" ${ }^{27}$.

El ciclo histórico diseñado por Cabrera se cierra así con la esperanza en el triunfo de las Luces de la mano del Monarca, pero diseñando para ello, en una especificidad propia de nuestro reformismo eclesiástico, un programa de estrecha colaboración entre Monarquia e Iglesia que, en los términos aquí expresados, convierte prácticamente a la primera en brazo secular de la segunda, aunque sea en aras del progreso y la lucha contra el fanatismo.

Completan la selección de textos realizada por Bails dos escritos de carácter normativo: sendas cartas pastorales del arzobispo de Toulouse, el célebre Loménie de Brienne, y del de Turín, promulgadas respectivamente en 1775 y 1777.

El papel de Loménie de Brienne fue importante en la creación de los cementerios extraurbanos en Francia. En gran medida se debió a su influencia el decreto prohibitivo emitido por el Parlamento de Toulouse el 3 de septiembre de 1774, que marcó un hito legislativo en la materia. En la Pastoral que recoge Bails, ligeramente posterior, habla del desorden "contra el cual nos urge providenciar" y postula la alianza entre poder civil y eclesiástico en términos algo menos drásticos que los utilizados por Cabrera:

«Reina tan sublime conformidad entre la religión y la política, que cuanto ésta reconoce honesto y útil la otra lo prescribe y manda" ${ }^{28}$.

De hecho, sin duda por mor de su personal experiencia, muestra un exquisito cuidado en deslindar claramente los ámbitos de lo religioso y lo civil y en despejar cualquier sospecha de intromisión eclesiástica, asunto especialmente importante en una Francia que a lo largo de todo el siglo XVIII se habia visto sacudida por fuertes controversias de índole político-religiosa ${ }^{29}$. Su critica moral se dirige contra la vanidad humana como fundamento de la perniciosa práctica del enterramiento en las iglesias: el creyente no debe desdeñar la sepultura común porque «...parece

\footnotetext{
${ }^{27}$ Págs. 153-154.

${ }^{28}$ Pág. 182.

${ }^{29}$ Págs. 201-202.
} 
que a lo menos la muerte debería poner todos los hombres a un nivel» ${ }^{30}$. Pero un claro índice del mucho mayor peso que adquieren en Francia las preocupaciones higienistas es el hecho de que, incluso en un documento tan especifico como una Carta Pastoral, la gran cuestión sea para el Arzobispo de Toulouse la siguiente:

"Si se permitieran entierros junto a las iglesias, ¿qué sería de la salubridad tan necesaria en las ciudades?" ${ }^{31}$.

Consecuencia de tales consideraciones es el decreto propiamente dicho. Desarrollado en 15 artículos, prohibe a los sacerdotes enterrar en el interior de las iglesias; se exceptúan los claustros y capillas contiguas, pero con obligación de construir bóvedas sepulcrales (para las que se establecen requisitos muy exactos) y con enumeración tajante de las personas que podrán enterrarse en ellas. Salvo dichas excepciones, se prescribe el enterramiento en los cementerios a cargo de cada iglesia y se establece, en consecuencia, en el artículo XI, la necesidad de que cada parroquia disponga de uun cementerio adecuado y apartado de toda habitación". De especial interés es el artículo XIII, que exige el cercamiento de los nuevos cementerios y su ubicación en lugares elevados y al norte de las viviendas "a fin de que el aire Sur, más perjudicial siempre que acarrea exhalaciones fétidas, ninguna pueda llevar a las viviendas de los vecinos" ${ }^{32}$.

La Carta Pastoral del Arzobispo de Turín, Francesco Lucerna Rorengo, de 1777, nos ofrece un interés suplementario al estar motivada de modo directo por la construcción en Turín de dos cementerios públicos a iniciativa real (cementerios cuya influencia en proyectos posteriores españoles ha sido señalada por C. Saguar). Desmarcándose un tanto de la apoyatura histórica buscada por los autores antes citados, el Arzobispo de Turín no duda en reconocer que no siempre estuvo en vigor la prohibición de enterramiento extramuros y busca basar su actuación no tanto en el recurso a la historia cuanto en la necesidad de solucionar problemas de la ciudad contemporánea. Es la suya una postura pragmática, un intento de dictar normas exigidas simplemente por una situación presente en la que la iniciativa regia ha marcado ya el tono, como queda claro en la exposición de motivos (en la cual, además, de modo significativo, se

\footnotetext{
30 Pág. 191.

31 Pág. 195.

32 Pág. 208.
} 
alude ya a estos nuevos cementerios con adjetivaciones tradicionalmente reservadas a las grandes obras civiles):

"Pero, ¿a qué se dirige todo ésto? A manifestaros, hijos y hermanos muy amados en Jesucristo, que si, atendiendo a los piadosísimos designios de nuestro Augusto Monarca, el cual, ansioso siempre de la felicidad de sus vasallos, ha hecho construir dos vastísimos y magníficos Cementerios fuera de las puertas de esta Ciudad, y a corta distancia de ellas, hemos resuelto establecer algunas reglas concernientes a los parajes en que deben sepultarse los fieles de esta Metrópoli, y de toda la Diócesis, no nos mueve a ello la inclinación a novedades, sino la honra y decoro de las Iglesias, el bien público y el deseo de asegurar en los posible que sean más frecuentados los templos" "33.

Fruto de este interés por los problemas prácticos concretos es el texto artículado del Decreto, que añade a las recomendaciones genéricas sobre cercamiento de los cementerios, aireación, etc., una serie de disposiciones sobre la arquitectura funeraria y su ornamentación.

Los tres primeros artículos de la parte normativa del texto establecen la prohibición genérica de enterrar en el interior de las Iglesias, las posibles excepciones (que se circunscriben a contadísimos casos de dignidades eclesiásticas) y la obligación de efectuar todas las demás inhumaciones en los dos cementerios públicos a que se ha hecho alusión. Los artículos IV al XVIII regulan, en consecuencia, de modo muy minucioso los ritos de inhumación, horario de los enterramientos, división de zonas en los cementerios públicos según las parroquias, como corresponde a la realidad de unos cementerios públicos extramuros ya en funcionamiento.

Sim embargo, quizás las disposiciones de mayor interés en el texto de Turín son las correspondientes a los artículos XIX y XXII, que se hacen eco de la tendencia a la privatización del espacio de la muerte mediante la construcción de tumbas suntuosas o panteones familiares que, sustituyendo a las antiguas capillas funerarias, reintroducen -al contrario de lo que anhelaba Loménie de Brienne - la desigualdad incluso después de la muerte.

El artículo XIX sanciona esta privatización del espacio público al permitir que se sitúen.

33 Pág. 246. 
"...bajo los pórticos que circundan, hermosean y hacen majestuosos dichos cementerios, sepulcros particulares para las personas y familias que hasta ahora los han tenido propios en las Iglesias de la ciudad".

Se cumple así la recomendación de Pierre Patte de que el cementerio público no significase, en modo alguno, una merma de la suntuosidad o el esplendor o el consejo dado también por Patte y recogido por Cabrera de templar ánimos: la misma "vanidad de los grandes" que se consideraba abusiva aplicada al interior de las iglesias encuentra ahora razón de ser en los nuevos cementerios públicos, si bien sometida ahora a un cierto control público y eclesiástico:

"...por todo lo dicho, en cuanto a Nos pertenece, permitimos que los Patronos o poseedores de estos sepulcros los puedan cerrar, con tal que lo hagan a sus propias expensas y según las instrucciones que se les diere por el arquitecto de su Majestad destinado para esta utilisima obra, reservándonos señalar el sitio particular para los sepulcros de las anunciadas personas o familias" ${ }^{34}$.

Este control, acerca de cuya extensión nada se dice, se diluye aún más, hasta convertirse en una norma de tono claramente más permisivo que restrictivo en el artículo XXII, que complementa lo dispuesto en el $\mathrm{XIX}$ estableciendo que

“...por lo que a Nos toca, no tenemos reparo en que sobre las paredes superiores, correspondientes a las bóvedas subterráneas, puedan ser Patronos o poseedores de sepulcros particulares poner escudos de armas, divisas, bustos, inscripciones, estatuas y otros semejantes adornos, o hacer pinturas decentes: siempre con la cláusula de observar la instrucción que diere el mencionado Real Arquitecto" ${ }^{35}$.

La Pastoral del Arzobispo de Turín nos interesa, así, de modo particular, por añadir a las fundamentaciones teóricas de carácter tanto higienista como cultural algunos de los primeros preceptos de orden práctico de organización y funcionamiento de un gran cementerio público y por

\footnotetext{
34 Pág. 254.

35 Pags. 254-255.
} 
poner sobre el tapete el pecualiar equilibrio con que se traslada al mundo de los muertos la dialéctica privado/público tan consustancial al nuevo universo ideológico.

Con al publicación conjunta de estos cuatro textos, con el diferente énfasis de cada uno de ellos en los distintos aspectos de la polémica, el libro de Bails se presenta asi como una auténtica condensación de los términos de un debate cuya resolución práctica se haría aún esperar hasta un nuevo siglo. Una recapitulación, a modo de conclusión, sobre los supuestos contenidos en la compilación de Bails deberá, sin duda, hacerse eco de la importante labor de éste como introductor en nuestro país de jalones importantes del pensamiento de las Luces o como decidido impulsor de debates ya iniciados. En cualquier caso, por más que la tacha de ausencia de originalidad sea irrefutable para muchas de sus obras, la trascendencia de sus intervenciones en el difícil contexto de las Luces hispánicas aleja la tentación de un análisis de su figura basado en estrictas consideraciones de derecho de autor y le coloca en el primer plano de la teoría arquitectónica y urbanística de nuestra llustración. 